\title{
High Temperature Performance Prediction Model of GAC-20 Modified Asphalt Mixture
}

\author{
Zhao-Hui SUN, Shuo ZHANG, Guang-Qiang ZHU, Qing LI
}

The Traffic Engineering School of Shenyang Jianzhu University, China

Keywords: High temperature performance, Prediction model, Fractal dimension

\begin{abstract}
GAC-20 modified asphalt mixture are designed by referencing the orthogonal design method, the high temperature rutting test are carried out , the related model of the fractal dimension and the high temperature performance evaluation index dynamic stability is established by using fractal theory. The high temperature performance of GAC-20 asphalt mixture can be predicted according to the gradation designed. This can reduce the test workload, improve work efficiency, and offer the reference for engineering design.
\end{abstract}

\section{Introduction}

The design of asphalt mixture has an important influence on asphalt pavement. There are a certain correlation between the distribution of asphalt mixture gradation and fractal theory. The correlation analysis can be carried out between the fractal dimension and the road performance. In this paper, we analyze the correlation between the fractal dimension and the high temperature performance evaluation index of asphalt mixture, and establish the correlation model between the fractal dimension and the pavement high temperature performance evaluation index. The road high temperature performance prediction model can be obtained.

\section{The Raw Material Performance Test}

Liaohe petroleum asphalt grade A No.90, which is widely used in the northeast of China and the basic performance test results are shown in Table 1, the basic performance test results of SBS modified asphalt are shown in Table 2. [1]

Table 1 Matrix asphalt technical index

\begin{tabular}{|c|c|c|c|}
\hline Detection index & Unit & Test value & Specification requirements \\
\hline Penetration $\left(25^{\circ} \mathrm{C}, 100 \mathrm{~g}, 5 \mathrm{~s}\right)$ & $0.1 \mathrm{~mm}$ & 86.3 & $80-100$ \\
\hline Ductility $\left(15^{\circ} \mathrm{C}\right)$ & $\mathrm{cm}$ & $>100$ & $\geq 50$ \\
\hline Softening Point $(\mathrm{R} \& \mathrm{~B})$ & ${ }^{\circ} \mathrm{C}$ & 45.9 & $\geq 45$ \\
\hline
\end{tabular}

Table 2 SBS Modified asphalt technical index

\begin{tabular}{|c|l|c|c|}
\hline Detection index & Unit & Test value & $\begin{array}{l}\text { Specification requirements } \\
\text { Conclusion }\end{array}$ \\
\hline Penetration $\left(25^{\circ} \mathrm{C}, 5 \mathrm{~s}, 100 \mathrm{~g}\right)$ & $0.1 \mathrm{~mm}$ & 83.6 & $80 \sim 100$ \\
\hline Softening Point(R\&B) & ${ }^{\circ} \mathrm{C}$ & 52.0 & $\geq 50$ \\
\hline Ductility $\left(5^{\circ} \mathrm{C}, 5 \mathrm{~cm} / \mathrm{min}\right)$ & $\mathrm{cm}$ & $>100$ & $\leq 30$ \\
\hline Kinematic viscosity $\left(135^{\circ} \mathrm{C}\right)$ & $\mathrm{Pa} \cdot \mathrm{s}$ & 2.7 & $\geq 90$ \\
\hline Elastic recovery $\left(25^{\circ} \mathrm{C}\right)$ & $\%$ & 91.2 & \\
\hline
\end{tabular}

The coarse and fine aggregate of GAC-20 mixture use limestone gravel produced by Liaoyang Xiaotun victory quarry. The basic performance test results are shown in table 3.[3] 


\section{HIGH TEMPERATURE Performance Test}

Using the orthogonal test method for reference to design 25 groups of GAC-20 modified asphalt mixture, the rutting test and water stability test were carried out under the wheel pressure is $0.84 \mathrm{MPa}$.

Table 3 Technical index of limestone coarse aggregate

\begin{tabular}{|c|c|c|c|c|c|c|c|}
\hline \multicolumn{2}{|c|}{ Material specification(mm) } & $\begin{array}{l}26.5-31 . \\
5\end{array}$ & 19-26.5 & 16-19 & $13.2-16$ & $9.5-13.2$ & 4.75-9.5 \\
\hline Technical index & $\begin{array}{l}\text { Standard } \\
\text { value }\end{array}$ & \multicolumn{6}{|c|}{ Test value } \\
\hline Crushing value(\%) & $\leq 24$ & \multicolumn{6}{|c|}{15} \\
\hline $\begin{array}{l}\text { Apparent relative } \\
\operatorname{density}\left(\mathrm{T} / \mathrm{m}^{3}\right)\end{array}$ & $\geq 2.5$ & 2.729 & 2.726 & 2.73 & 2.718 & 2.729 & 2.732 \\
\hline $\begin{array}{l}\text { Water } \\
\text { rate(\%) }\end{array}$ & $\leq 2.0$ & 0.12 & 1.18 & 0.26 & 0.28 & 0.38 & 0.62 \\
\hline $\begin{array}{ll}\begin{array}{l}\text { Adhesion } \\
\text { asphalt(Grade) }\end{array} & \text { with } \\
\end{array}$ & $\geq 4$ & \multicolumn{6}{|c|}{4} \\
\hline Consistency(\%) & $\leq 8$ & \multicolumn{6}{|c|}{8} \\
\hline $\begin{array}{l}\text { Content of needle and } \\
\text { sheet granular(\%) }\end{array}$ & $\leq 12$ & \multicolumn{6}{|c|}{12} \\
\hline $\begin{array}{l}<0.075 \text { Particle } \\
\text { content(\%) }\end{array}$ & $\leq 1$ & \multicolumn{2}{|c|}{0.3} & 0.3 & 0.3 & 0.3 & 0.3 \\
\hline
\end{tabular}

Grade A No.90 road petroleum asphalt, SBS modified additives and limestone were tested in accordance with the requirements of the road usage.

Test results are shown in table 4.

The technical requirements for the dynamic stability of asphalt mixture rutting test are different according to different climate zones and the type of asphalt and mixture in the current specification, Climate zoning in the Northeast of China is belonging to the 2-1 (hot in summer and severe cold in winter) area and 2-2 (hot in summer and cold in winter) area, due to the wheel pressure 0.84 MPa was adopted in rutting test, dynamic stability should be reduced from relevant literature to meet greater than or equal to 2000 times / mm. Therefore, the high temperature stability of GAC-20 mixture with the grading number of $3,8,11,13,9,17$ and 24 can meet the requirements.

Table 4 The results of GAC-20 Rutting test(times/mm)

\begin{tabular}{|l|c|c|}
\hline \multicolumn{1}{|c|}{ Gradation } & The optimum asphalt aggregate ratio /\% & $D S_{0}$ \\
\hline GAC-20-1 & 4.26 & 1182 \\
\hline GAC-20-2 & 4.26 & 1432 \\
\hline GAC-20-3 & 4.40 & 3103 \\
\hline GAC-20-4 & 4.27 & 1892 \\
\hline GAC-20-5 & 4.27 & 593 \\
\hline GAC-20-6 & 4.29 & 1869 \\
\hline GAC-20-7 & 4.30 & 712 \\
\hline GAC-20-8 & 4.30 & 2192 \\
\hline GAC-20-9 & 4.21 & 2042 \\
\hline GAC-20-10 & 4.26 & 4733 \\
\hline GAC-20-11 & 4.24 & 2413 \\
\hline GAC-20-12 & 4.32 & 1645 \\
\hline GAC-20-13 & 4.30 & 3124 \\
\hline GAC-20-14 & 4.26 & 1079 \\
\hline
\end{tabular}




\begin{tabular}{|l|c|c|}
\hline Gradation & The optimum asphalt aggregate ratio $/ \%$ & $D S_{0}$ \\
\hline GAC-20-15 & 4.26 & 1207 \\
\hline GAC-20-16 & 4.26 & 602 \\
\hline GAC-20-17 & 4.27 & 4827 \\
\hline GAC-20-18 & 4.27 & 1261 \\
\hline GAC-20-19 & 4.29 & - \\
\hline GAC-20-20 & 4.30 & 1690 \\
\hline GAC-20-21 & 4.23 & - \\
\hline GAC-20-22 & 4.21 & 805 \\
\hline GAC-20-23 & 4.26 & 905 \\
\hline GAC-20-24 & 4.24 & 3745 \\
\hline GAC-20-25 & 4.32 & 595 \\
\hline
\end{tabular}

Note:"-"indicate the test data is not listed in the table, it needs further verification.

\section{HIGH TEMPERATURE Performance Model}

The rutting test results of meeting the above high temperature stability requirements in the Northeast of China and the corresponding fractal dimension are summarized in Table 5.

Table 5 GAC-20 grading fractal dimension and dynamic stability data

\begin{tabular}{|l|c|c|c|c|}
\hline Grading & $\begin{array}{c}\text { Grading fractal } \\
\text { dimension D }\end{array}$ & $\begin{array}{c}\text { Coarse aggregate } \\
\text { fractal dimension } \mathrm{D}_{\mathrm{c}}\end{array}$ & $\begin{array}{c}\text { Fine aggregate fractal } \\
\text { dimension } \mathrm{D}_{\mathrm{f}}\end{array}$ & $\begin{array}{c}\text { Dynamic } \\
\text { stability DS } \\
\text { (times/mm) }\end{array}$ \\
\hline GAC-20-3 & 2.5665 & 2.4692 & 2.4484 & 3103 \\
\hline GAC-20-8 & 2.5739 & 2.5044 & 2.4017 & 2192 \\
\hline GAC-20-9 & 2.5367 & 2.4487 & 2.5468 & 2042 \\
\hline GAC-20-10 & 2.5369 & 2.6229 & 2.3127 & 4733 \\
\hline GAC-20-11 & 2.5026 & 2.3988 & 2.4749 & 2413 \\
\hline GAC-20-13 & 2.4535 & 2.5041 & 2.3420 & 3124 \\
\hline GAC-20-17 & 2.5394 & 2.4417 & 2.3571 & 4827 \\
\hline GAC-20-24 & 2.5835 & 2.5044 & 2.4632 & 3745 \\
\hline
\end{tabular}

As can be seen from table 5, the fractal dimension range of meeting the requirement of dynamic stability is $\mathrm{D}=[2.4535,2.5835], \mathrm{Dc}=[2.3988,2.6229], \mathrm{Df}=[2.3127,2.5468]$. There is a correlation between the high temperature performance of asphalt mixture and fractal dimension. First of all, three element linear regression is analyzed between the fractal dimension Dree element linear regression model of dynamic stability and fractal dimension is established. The residual chart of dynamic stability and fractal dimension is drawn by the software MATLAB in Figure 2 to check out the abnormal data. The regression analysis is done after the abnormal point is eliminated to get more accurate regression model.

It can be seen From Figure 2, except for the second data, the residual of the rest data is close to the zero point, and the confidence interval of the residuals contains zero. The confidence interval contains zero point, which shows that the regression model can meet the original data. The second data can be regarded as abnormal points in the data analysis, it should be removed when the regression analysis is done again.That is excluding the second data, three element linear regression analysis is done to obtain the correlation model of dynamic stability. The regression coefficient $\mathrm{R}^{2}=0.937$, As can be seen in formula (2).

$$
\text { DS=3206.5+16056.8D-2605.5Dc-14025.4Df }
$$




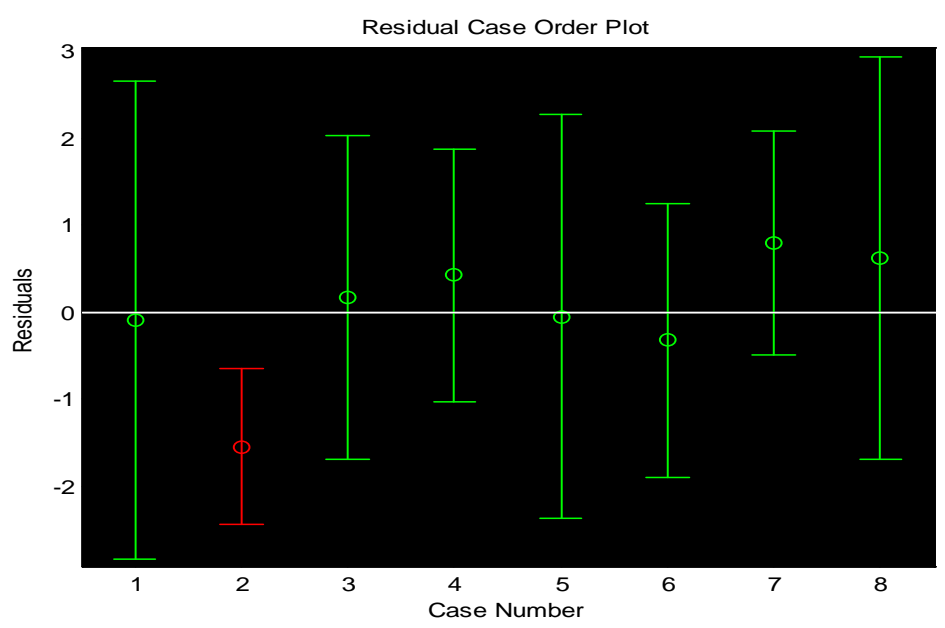

Figure 2The residual chart of dynamic stability and fractal dimension

Table 6 The correlation of dynamic stability and fractal dimension

\begin{tabular}{|c|c|c|c|c|}
\hline & $\mathrm{DS}$ & $\mathrm{D}$ & $\mathrm{D}_{\mathrm{c}}$ & $\mathrm{D}_{\mathrm{f}}$ \\
\hline $\mathrm{DS}$ & 1.000 & 0.123 & 0.283 & 0.072 \\
\hline $\mathrm{D}$ & 0.123 & 1.000 & -0.621 & 0.477 \\
\hline $\mathrm{D}_{\mathrm{c}}$ & 0.283 & -0.621 & 1.000 & -0.685 \\
\hline $\mathrm{D}_{\mathrm{f}}$ & 0.072 & 0.477 & -0.685 & 1.000 \\
\hline
\end{tabular}

This can be shown that the three element linear regression model can be established between dynamic stability and fractal dimension, and the regression coefficient is higher, so there are the correlation between dynamic stability and the fractal dimension, the correlation analysis is done by data in Table 5, the correlation analysis results are shown in Table 6.

It can be seen from table 6 , the correlation between the fractal dimension and DS ordered from the big to small is $\mathrm{D}_{\mathrm{C}}>\mathrm{D}>\mathrm{D}_{\mathrm{f}}$. The influence of coarse aggregate fractal dimension on dynamic stability is relatively large, but the correlation coefficient of DS and the coarse aggregate fractal dimension is relatively small. The correlation between $\mathrm{D}_{\mathrm{f}}$ and DS is lower, the correlation between the stability and the coarse aggregate is the largest through the analysis of the correlation between the dynamic stability and the fractal dimension, so the correlation model between the fractal dimension of the coarse aggregate and the dynamic stability can be established. The related model of dynamic stability $\mathrm{DS}$ and $\mathrm{D}_{\mathrm{c}}$ is shown in formula (3).

$$
\text { DS }=42052 D_{c}^{2}-203689 D_{c}+249584
$$

The regression coefficient $\mathrm{R}^{2}=0.2639$

The correlation among dynamic stability and fractal dimension D, Dc is relatively larger than that of dynamic stability and Df. The correlation model of dynamic stability and two fractal dimensions $\mathrm{D}, \mathrm{Dc}$ is established. As is shown in formula (4).

$$
\mathrm{DS}=-22878.3-862.6 \mathrm{D}+11277.1 \mathrm{D}_{\mathrm{c}}
$$

The regression coefficient $\mathrm{R}^{2}=0.6575$

The correlation model of dynamic stability and two fractal dimensions $D_{c}, D_{f}$ is established. As is shown in formula (5).

$$
\mathrm{DS}=20934.2+1360.2 \mathrm{D}_{\mathrm{c}}-8702.0 \mathrm{D}_{\mathrm{f}}
$$

The regression coefficient $\mathrm{R}^{2}=0.4733$ 


\section{Model Selection}

The correlation model of dynamic stability and fractal dimension established is included in Table 7. It can be seen from table 7 that the prediction accuracy of three element linear model is higher than the others. Thus, the model 1 is recommended to predict the dynamic stability by model selection.

Table 7 Prediction model of dynamic stability

\begin{tabular}{|l|l|c|l|}
\hline No. & \multicolumn{1}{|c|}{ Model expression } & $\begin{array}{l}\text { Regression } \\
\text { coefficient } \\
\mathrm{R}^{2}\end{array}$ & \multicolumn{1}{|c|}{ Characteristics } \\
\hline 1 & $\begin{array}{l}\mathrm{DS}=3206.5+16056.8 \mathrm{D}-2605.5 \mathrm{D}_{\mathrm{c}}-14 \\
025.4 \mathrm{D}_{\mathrm{f}}\end{array}$ & 0.937 & $\begin{array}{l}\text { The regression coefficient is } \\
\text { higher and the analysis of } \\
\text { the factor is more } \\
\text { comprehensive }\end{array}$ \\
\hline 2 & $\mathrm{DS}=42052 \mathrm{D}_{\mathrm{c}}{ }^{2}-203689 \mathrm{D}_{\mathrm{c}}+249584$ & 0.2639 & $\begin{array}{l}\text { The regression coefficient is } \\
\text { low and the analysis of the } \\
\text { influence factors is } \\
\text { relatively simple }\end{array}$ \\
\hline 3 & $\mathrm{DS}=-22878.3-862.6 \mathrm{D}+11277.1 \mathrm{D}_{\mathrm{c}}$ & 0.6575 & $\begin{array}{l}\text { The regression coefficient is } \\
\text { lower }\end{array}$ \\
\hline 4 & $\mathrm{DS}=20934.2+1360.2 \mathrm{D}_{\mathrm{c}}-8702.0 \mathrm{D}_{\mathrm{f}}$ & 0.4733 & $\begin{array}{l}\text { The regression coefficient is } \\
\text { lower }\end{array}$ \\
\hline
\end{tabular}

\section{Conclusions}

By the results of the above experiments and the model, the prediction model of high temperature performance of GAC-20 mixture is DS=3206.5+16056.8D-2605.5D $-14025.4 \mathrm{D}_{\mathrm{f}}$; The water stability prediction model is $\mathrm{DSR}=-1.2919+0.3012 \mathrm{D}+0.3414 \mathrm{D}_{\mathrm{c}}+0.2462 \mathrm{D}_{\mathrm{f}}$ or DSR $=-1.0483+0.4426 \mathrm{Dc}+0.3553 \mathrm{Df}$.

These models are used to predict the performance of GAC-20 mixture, it can reduce the amount of testing, improve the working efficiency, and can be used for engineering design.

\section{Acknowledgements}

This work was financially supported by the Natural Science Foundation of China (51178278)

\section{References}

[1]Occupation Standard of the People’s Republic of China., JTG E20-2011 “Standard Test Methods of Bitumen and Bituminous Mixtures for Highway Engineering” [S]

[2]Highway Science Research Institute, Ministry of Communications JTG F40-2004 "Technical Specifications for Construction of Highway Asphalt Pavements” [S]

[3]Occupation Standard of the People's Republic of China, JTG E42-2005 "Test Methods of Aggregate for Highway Engineering”, [S]

[4]Nukunya,B., R.Roque,M.Tia,B. Birgisson. Evaluation of VMA and other Volumetric Properties as Criteria for the Design and Acceptance of Superpave Mixtures[J].Journal of the Association of Asphalt Paving Technologists, 2002, Vol.79,pp.38-69

[5]Zhao-Hui SUN, Tie-Bin WANG, Ze-Feng WU and Zhi-Song WANG, Research on the Evaluation Method of Water Stability for Large Size aggregate Particle Asphalt Mixture Applied Mechanics and Materials Vol. 692 (2014) pp 497-500 Submitted: 10.09.2014 
[6]Al-Swailmi S., Evaluation of Water Damage of Asphalt Concrete Mixtures

Using the Environmental Conditioning System (ECS). Proceedings, 2012.

[7]Feodor M. Borodich. Fractals and fractal scaling in fracture mechanics[J]International Journal of Fracture. 1999,(95):239-259

[8]Faleoner,Fractal Geometry: Mathematical Foundation and Applications, Wiely,NewYork,1990

[9]Lee. H., Carr, Barr J. \& Haas J, The Fractal Dimension as a Measure of the Roughness of Rock Discontinuity profiles[J], International Journal of Rock,1990

[10]Ribble, C., Szecsy, R. and Zollinger, D.G. Aggregate macro shape and micro texture in concrete mix design[J]. ASCE Spring Meeting, New York, 1992

[11]Joseph K. Anochie-Boateng, Julius Komba, and Erol Tutumluer Aggregate Surface Areas Quantified through Laser Measurements for South African Asphalt Mixtures[J]Journal of Transportation Engineering Vol.138, No.8, pp. 1006-1015 Aug 2012.

[12]W.H. Campen, et al, Relationship Between Voids, Surface Area, Film Thickness, and stability in Bituminous Paving Mixtures[J], Proc. AAPT, Vol. 28, 1959.

[13]Adhara Castelblanco Torres. Probabilistic Analysis of Air Void Structure and Its Relationship to Permeability and Moisture Damage of Hot Mix Asphalt [D]Texas A\&M University.2004

[14]Xinjun Li, R.Christopher Williams, Mihai O. Marasteanu, Timothy R. Clyne, Eddie Johnson. Investigation of In-Place Asphalt Film Thickness and Performance of Hot-Mix Asphalt Mixtures[J]Journal of Materials in Civil Engineering 2009 (21) $\mathrm{P}_{262-270}$

[15]Leonardi, G.Fractal dimension for the characterization of the porosity of asphalt concretes[J].Archives of Civil Engineering, v 56, n 4, p 321-333, December 1, 2010 